\title{
Clinical Profile of Neonates with Respiratory Distress in a Tertiary Care Hospital
}

\author{
Anita Lamichhane, ${ }^{1}$ Kiran Panthee, ${ }^{2}$ Sharmila Gurung ${ }^{3}$ \\ 'Department of Pediatrics, Lumbini Medical College, Pravas, Palpa, Nepal, ${ }^{2}$ Department of Pediatrics, Devdaha Medical \\ College, Bhaluhi, Rupandehi, Nepal, ${ }^{3}$ Department of Forensic Medicine, Devdaha Medical College, Bhaluhi, Rupandehi, \\ Nepal.
}

Introduction: Respiratory distress in newborns is a very common reason for admission in Neonatal Intensive Care Unit which may be transient or pathological; morbidity is high if not prompted for early diagnosis and treatment. The present study is undertaken to find out the clinical profile of neonates with respiratory distress in infants in a tertiary care hospital in western Nepal.

Methods: A descriptive cross-sectional study was carried out in a tertiary care hospital in the western region of Nepal from April 2017 to March 2018 after approval from the Institutional Review Committee. Convenience sampling was done. Data were collected from the study population after taking consent and entered in a predesigned proforma. Data was then entered in a Statistical Package for Social Sciences for further calculations.

Results: Tachypnea was the most common presentation 77 (69.36\%). Out of 1694 live deliveries during the study period, the prevalence of respiratory distress was $6.55 \%$ in the total live deliveries while $30.83 \%$ in admitted cases in Neonatal Intensive Care Unit. Survival rate was 95.50\% while mortality rate accounted for $4.50 \%$.

Conclusions: Perinatal asphyxia accounted for the commonest cause of respiratory distress. To lessen the morbidity and mortality of the neonates with respiratory distress it is advocated that we practice proper and timely neonatal resuscitation, recognize the risk factors as early as possible so that perinatal asphyxia can be minimized.

Keywords: neonatal intensive care unit; neonates; respiratory distress.

\section{INTRODUCTION}

Globally respiratory distress in newborns is the most common presentation which requires hospital admission. Saeed $Z$ et al. described respiratory distress as the most common presenting problem encountered within the first $48-72$ hours of life with a prevalence of $4.24 \%$ in neonates. ${ }^{1}$
The most common causes of respiratory distress include Transient Tachypnea of the Newborn (TTN), Hyaline Membrane Disease (HMD), Birth asphyxia, Pneumonia

Correspondence: Dr. Anita Lamichhane, Department of Pediatrics, LumbiniMedicalCollegeandTeaching Hospital,Pravas,Palpa, Nepal. Email: anitalamee@gmail.com, Phone: +977-9843359884. 
and Meconium Aspiration Syndrome (MAS). ${ }^{2}$ There are studies which have reported the incidence of respiratory distress in newborn babies to be ranging from 3.9 to 8 $\%$ in admitted patients in Neonatal Intensive Care Unit (NICU). ${ }^{3,4}$

There has been tremendous advances in the treatment of neonatal respiratory distress syndrome but very few clinical studies have been conducted in our country. So this study was undertaken to find out the clinical profile of babies with respiratory distress.

\section{METHODS}

This descriptive cross-sectional study was conducted in the neonatal intensive care unit (NICU) of Devdaha Medical College and Teaching Hospital (LMCTH) in Western Nepal from April 2017 to March 2018 at Devdaha Medical College, Bhaluhi, Rupandehi, Nepal after taking approval from the institutional review committee (IRC) of the college.

The present study included all the term and preterm neonates who developed respiratory distress within 48 hours after birth, both inborn and outborn and singleton babies. Those neonates who developed respiratory distress 48 hours after birth and having congenital anomalies like congenital diaphragmatic hernia, anencephaly, and meningomyelocele and twin babies were excluded from the study. A written consent was obtained from the mother for the participation in the study for their newborn neonates.

Respiratory distress was diagnosed based clinically when two out of the following were present.
a) Tachypnea (respiratory rate $>60$ breaths $/ \mathrm{min}$ )
b) Nasal flaring
c) Intercostal recession
d) Subcostal recession
e) Grunting

A detailed history regarding birth weight, maternal age, gestational age at the time of delivery, sex, mode and place of delivery, maternal risk factors, meconium stained liquor, was taken from the mother and entered in the predesigned proforma. After admission in the NICU, babies were thoroughly examined and monitored daily till discharge from the hospital or death. They were treated as per the NICU protocols of the hospital having specified indications for oxygen therapy, CPAP, mechanical ventilation. Relevant investigations like full blood count, C-reactive protein, blood glucose, blood cultures, blood gases, chest x-ray were sent. In case of death, the cause of mortality was recorded. Severity of distress was assessed by Anderson Silverman Score. ${ }^{5}$
Based on this score, the babies with respiratory distress were categorized in three groups. These were mild (1-3 score), moderate (4-6 score), severe ( $>6$ score).

Data was checked for any errors or inconsistencies, then entered in Microsoft Excel sheets and analysed using Statistical Package for Social Sciences (SPSS) version 25.0 .

Convenience sampling and the sample size was calculated using the formula, ${ }^{6}$

$$
\begin{aligned}
n & =Z^{2} \times(p \times q) / e^{2} \\
& =1.96^{2} \times 0.08 \times(1-0.08) / 0.05^{2} \\
& =113
\end{aligned}
$$

where,

$\mathrm{n}=$ required sample size

$p=$ prevalence of respiratory distress $(8 \%)^{3}$

$q=1-p$

$\mathrm{e}=$ margin of error, $5 \%$

$\mathrm{Z}=1.96$ at $95 \% \mathrm{Cl}$

Total sample size was calculated to be 113 .

\section{RESULTS}

The most common presentation of respiratory distress was tachypnea, 77 (69.36\%) (Table 1). Out of 1694 live deliveries during the study period, 360 (21.25\%) neonates were admitted to NICU. Out of them 168 (46.6\%) babies fulfilling the inclusion and exclusion criteria were included in the study. Mothers of fifty seven babies did not give consent for the study. So, 111 (30.83\%) cases fulfilling the inclusion and exclusion criteria were enrolled in the study giving prevalance of $6.55 \%$ in the total live deliveries. The mean weight of the babies was $2.25 \pm 0.63 \mathrm{~kg}$. Respiratory distress was common (61.26\%) in the low birth weight babies $(<2.5 \mathrm{Kg})$. The demographic profile of the babies are shown (Table 2). Anderson Silverman scoring showed that there were $24(21.62 \%)$ neonates in mild category, $75(67.57 \%)$ in moderate category while severe category had $12(10.82 \%)$ neonates. Survival rate was 106 (95.50\%) while mortality accounted for 05 (4.50\%) (Table 3).

\begin{tabular}{|ll|}
\hline \multicolumn{2}{|l|}{$\begin{array}{l}\text { Table 1. Showing the clinical features of neonates } \\
\text { with respiratory distress. }\end{array}$} \\
\hline Clinical presentation & $\mathrm{n}(\%)$ \\
Tachypnea & $77(69.36)$ \\
Chest in drawing & $10(09.01)$ \\
Cyanosis & $3(2.70)$ \\
Poor perfusion & $3(2.70)$
\end{tabular}




\begin{tabular}{|ll|} 
Grunting & $14(12.61)$ \\
Nasal flaring & $4(3.60)$ \\
\hline
\end{tabular}

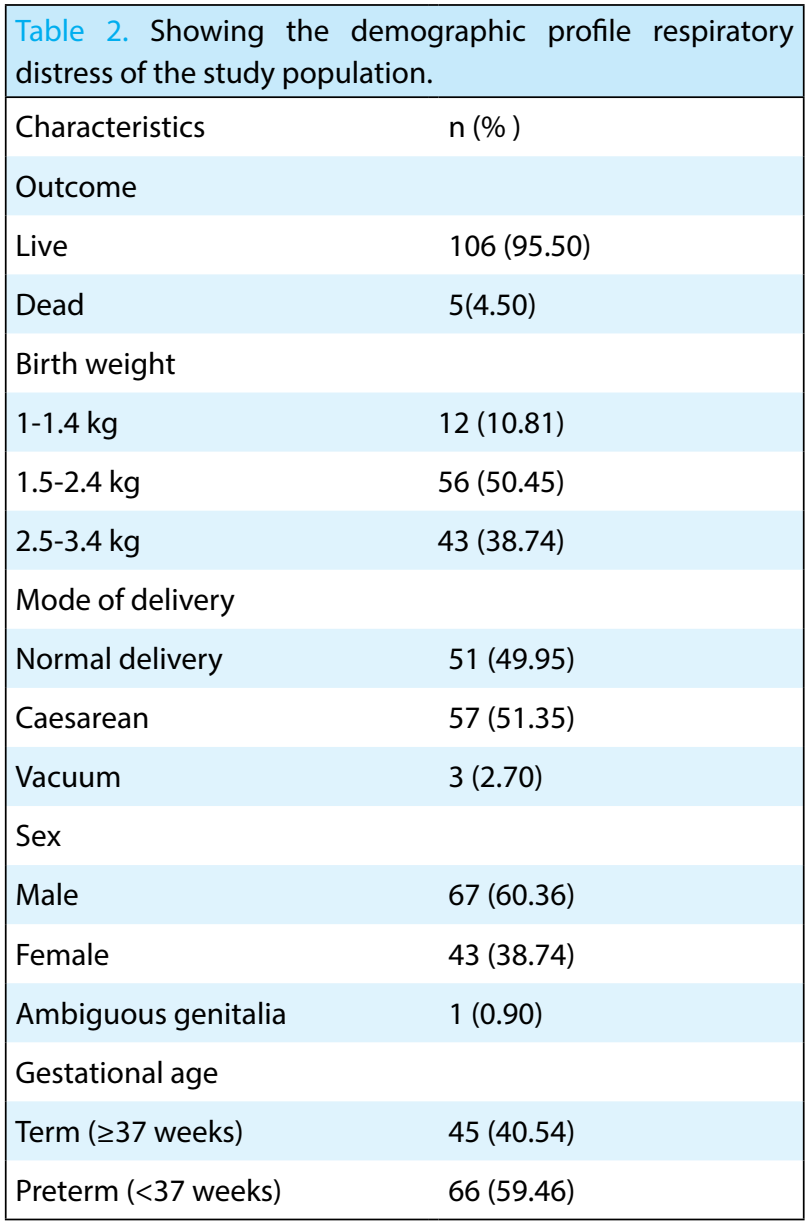

\begin{tabular}{|c|c|c|c|}
\hline & n (\%) & Survived & Expired \\
\hline $\begin{array}{l}\text { Mild respiratory } \\
\text { distress }(1-3)\end{array}$ & $\begin{array}{l}24 \\
(21.62)\end{array}$ & $\begin{array}{l}23 \\
(99.83)\end{array}$ & $1(4.17)$ \\
\hline $\begin{array}{l}\text { Moderate } \\
\text { respiratory } \\
\text { distress (4-6) }\end{array}$ & $\begin{array}{l}75 \\
(67.57)\end{array}$ & $\begin{array}{l}73 \\
(97.33 \%\end{array}$ & $2(2.67)$ \\
\hline $\begin{array}{l}\text { Severe } \\
\text { respiratory } \\
\text { distress 9>6) }\end{array}$ & $\begin{array}{l}12 \\
(10.81)\end{array}$ & $9(8.11)$ & $2(1.80)$ \\
\hline Total & $\begin{array}{l}111 \\
(100 \%)\end{array}$ & $\begin{array}{l}106 \\
(95.50 \%)\end{array}$ & $\begin{array}{l}5 \\
(4.50 \%)\end{array}$ \\
\hline
\end{tabular}

\section{DISCUSSION}

During the study period out of 1694 deliveries and 360 NICU admissions, 111 (30.83\%) neonates developed respiratory distress making an incidence of $6.55 \%$ in total population and $30.83 \%$ in admitted babies. This is similar to studies done in Nepal which showed the incidence ranging from $3.9 \%$ to $8.0 \%$ in total population. $^{3,5}$ There are some other studies confirming respiratory distress is common in neonates and occurs in approximately $7 \%$ of babies during the neonatal period. ${ }^{7,8}$ Another study done by Malik et al. showed $47.2 \%$ incidence of respiratory distress of NICU admissions. ${ }^{9}$

Other studies had different incidences ranging from 20 to $50 \% .^{10,11}$ This is quite similar to studies done in India $(60.62 \%)^{12}$ and Bangladesh (505.3\%). ${ }^{13}$ This high rate may be due to the vulnerability of the LBW babies predisposing to respiratory problems and infections. Tachypnea was the most common presentation (69.36\%).

Most of the babies with respiratory distress were delivered by caesarean section $(51.35 \%)$ while normal vaginal delivery accounted for $49.95 \%$. This is in contrast to a study done in India ${ }^{11}$ and Nepal ${ }^{7}$ which showed that vaginal delivery was more commonly associated with the development of respiratory distress in newborn babies. This high rate of caesarean section associated with respiratory distress may be due to that fluid clearance may be a bit delayed in babies contributing to developing distress.

There was male preponderance in our study (60.36\%) as compared to female babies (38.74\%). ${ }^{14}$ This is comparable to another study done by Miller et al. which showed incidence of respiratory distress was almost three times higher in male babies than in female babies. Similar studies by Kanodia, ${ }^{15} \mathrm{Mmbaga}^{16}$ and Shah $\mathrm{GS}^{2}$ reported male predominance. Male babies are likely to be affected 2-4 times more than female babies. ${ }^{17}$ There is a presence of gender bias still in all regions and cultures and hence male babies are brought to the hospital in more number. This may be one of the reason for male preponderance.

The survival rate was good in our study $(95.50 \%)$ while mortality accounted for $4.50 \%$. This low mortality may be due to prompt recognition of the symptoms and treatment.

There were certain limitations of our study. It was a small sample sized hospital based study done in a certain limited time. A large population based study will be needed to strengthen our study. 
Respiratory distress embraced $6.55 \%$ of all total live deliveries while it constituted $30.83 \%$ of all NICU admission. To lessen the morbidity and mortality of the neonates with respiratory distress it is advocated that we practice proper and timely neonatal resuscitation, recognize the risk factors as early as possible so that perinatal asphyxia can be minimized. We should also advocate good obstetric care.

Conflict of Interest: None.

\section{REFERENCES}

1. Zaman S, Goheer L, Riaz H. Prevalence and aetiology of respiratory distress in newborns. Pak Armed Forces Med J. 2013;63(1):22-5. [Full Text]

2. Shah G, Yadav S, Thapa A, Shah L. Clinical Profile and Outcome of Neonates Admitted to Neonatal Intensive Care Unit (NICU) at a Tertiary Care Centre in Eastern Nepal. JNPS. 2013;33(3):177-81. [Full Text | DOI]

3. Shrestha S, Shah A, Prajapati R, Sharma Y. Profile of Neonatal Admission at Chitwan Medical College. JCMC. 2014 ;3(4):13-6. [ Full Text | DOI]

4. Bajad M, Goyal S, Jain B. Clinical profile of neonates with respiratory distress. IJCP. 2016;3(3):1009-13. [Full Text | DOI]

5. Hedstrom AB, Gove NE, Mayock DE, Batra M. Performance of the Silverman Andersen Respiratory Severity Score in predicting $\mathrm{PCO}_{2}$ and respiratory support in newborns: a prospective cohort study. J Perinatol 2018;38(5):505-11. [Full Text $\mid \underline{D O I}$

6. Charan J, Biswas T. How to calculate sample size for different study designs in medical research? Indian J Psychol Med. 2013;35(2):121-6. [PubMed | Full Text | DOI]

7. Parkash A, Haider N, Khoso ZA, Shaikh AS. Frequency, causes and outcome of neonates with respiratory distress admitted to Neonatal Intensive Care Unit, National Institute of Child Health, Karachi. JPMA. 2015;65:771-5. [Full Text]

8. Edwards MO, Kotecha SJ, Kotecha S. Respiratory distress of the term newborn infant. Paediatr Respir Rev. 2013;14(1):29-36. [ PubMed | Full Text | DOI]

9. Malik S, Gohiya P, Khan IA. Morbidity profile and mortality of neonates admitted in Neonatal Intensive Care Unit of a Central India Teaching Institute: A prospective observational study. J Clin Neonatol. 2016;5:168-73. [Full Text | DOI]

10. Shreshtha S, Sharma A, Upadhyay S, Rijal P. Perinatal mortality audit. Nepal Med Coll J. 2010;12(4):257-9. [ㅍull Text]
11. Omoigberale AI, Sadoh WE, Nwaneri DU. A 4 year review of neonatal outcome at the University of Benin Teaching Hospital, Benin City. Niger J Clin Pract 2010;13(3):3215. [PubMed | Full Text]

12. Rakholia R, Rawat V, Mehar B, Singh G. Neonatal morbidity and mortality of sick newborns admitted in a teaching hospital of Uttarkhand. Chrismed J Health Research 2014;1(4):228-34. [Full Text]

13. Klemm RD, Merrill RD, Wu L, Shamim AA, Ali H, Labrique A, et al. Low-birthweight rates higher among Bangladeshi neonates measured during active birth surveillance compared to national survey data. Matern Child Nutr 2015 Oct;11(4):583-94. [PubMed | Full Text | DOI]

14. Miller HC. Respiratory Distress Syndrome of Newborn Infants: III. Statistical Evaluation of Factors Possibly Affecting Survival of Premature Infants. Pediatrics. 1963;31(4):573-9. [Full Text]

15. Kanodia P, Yadav SK, Bhatta NK, Singh RR. Disease profile and outcome of newborn admitted to neonatology unit of BPKIHS. J Col Med Sci Nepal 2015; 11(3): 20-4. [Full Text | DOI]

16. Mmbaga BT, Lie RT, Olimi R, Mahande MJ, Kvale G, Daltveit AK. Cause-specific neonatal mortality in a neonatal care unit in Northern Tanzania: a registry based cohort study. BMC Pediatrics. 2012;12:116. [Full Text]

17. Mishra P. Respiratory distress in newborn. Indian Pediatr.1987;24:77-80. [PubMed] 